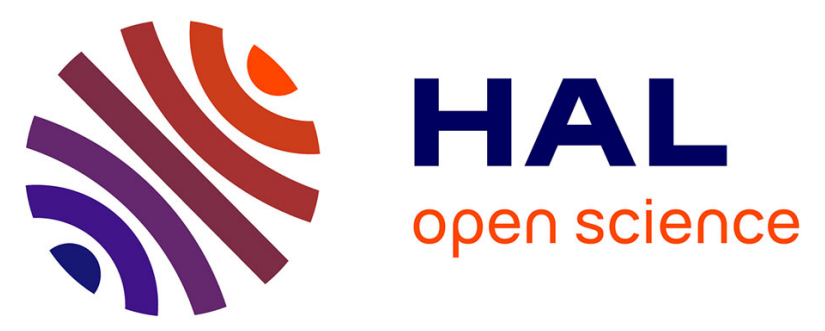

\title{
Ecophysiological and phytochemical characterization of wild populations of Inula montana L. (Asteraceae) in Southeastern France
}

David Roux, Osama Alnaser, Elnur Garayev, Béatrice Baghdikian, Riad Elias, Philippe Chiffolleau, Evelyne Ollivier, Sandrine Laurent, Mohamed El Maataoui, Huguette Sallanon

\section{To cite this version:}

David Roux, Osama Alnaser, Elnur Garayev, Béatrice Baghdikian, Riad Elias, et al.. Ecophysiological and phytochemical characterization of wild populations of Inula montana L. (Asteraceae) in Southeastern France. Flora, 2017, 236-237, pp.67 - 75. 10.1016/j.flora.2017.09.012 . hal-01765072

\section{HAL Id: hal-01765072 \\ https://hal-amu.archives-ouvertes.fr/hal-01765072}

Submitted on 12 Apr 2018

HAL is a multi-disciplinary open access archive for the deposit and dissemination of scientific research documents, whether they are published or not. The documents may come from teaching and research institutions in France or abroad, or from public or private research centers.
L'archive ouverte pluridisciplinaire HAL, est destinée au dépôt et à la diffusion de documents scientifiques de niveau recherche, publiés ou non, émanant des établissements d'enseignement et de recherche français ou étrangers, des laboratoires publics ou privés. 


\title{
Ecophysiological and phytochemical characterization of wild populations of Inula montana L. (Asteraceae) in Southeastern France
}

\author{
David Roux ${ }^{\mathrm{a}, \mathrm{b}, *}$, Osama Alnaser ${ }^{\mathrm{a}, \mathrm{b}}$, Elnur Garayev ${ }^{\mathrm{c}}$, Béatrice Baghdikian ${ }^{\mathrm{c}}$, Riad Elias ${ }^{\mathrm{c}}$, \\ Philippe Chiffolleau ${ }^{\mathrm{d}}$, Evelyne Ollivier ${ }^{\mathrm{c}}$, Sandrine Laurent ${ }^{\mathrm{a}, \mathrm{b}}$, Mohamed El Maataoui ${ }^{\mathrm{a}, \mathrm{b}}$, \\ Huguette Sallanon ${ }^{\mathrm{a}, \mathrm{b}}$ \\ a Avignon University, Qualisud UMR95, F-84 000 Avignon, France \\ b Qualisud, Univ Montpellier, CIRAD, Montpellier Sup'Agro, Université d'Avignon, Université de la Réunion, Montpellier, France \\ c Aix Marseille Univ, Laboratory of Pharmacognosy and Ethnopharmacology, UMR-MD3, Faculty of Pharmacy, 27 Bd Jean Moulin, CS 30064, 13385, Marseille cedex \\ 05, France \\ d Luberon Natural Regional Park, 60 place Jean-Jaurès, BP 122, 84404 Apt, France
}

Keywords:

Sesquiterpene lactones

Flavonoids

Phytochemistry

Drought

Secondary metabolites

Plant morphology

Altitudinal gradient

\begin{abstract}
A B S T R A C T
Inula montana is a member of the family Asteraceae and is present in substantial numbers in Garrigue country (calcareous Mediterranean ecoregion). This species has traditionally been used for its anti-inflammatory properties as well as Arnica montana. In this study, three habitats within Luberon Park (southern France) were compared regarding their pedoclimatic parameters and the resulting morpho-physiological response of the plants. The data showed that $I$. montana grows in south-facing poor soils and tolerates large altitudinal and temperature gradients. The habitat conditions at high elevation appear to affect mostly the morphology of the plant (organ shortening). Although the leaf contents of total polyphenols and flavonoids subclass essentially followed a seasonal pattern, many sesquiterpene lactones were shown to accumulate first at the low-elevation growing sites that suffered drought stress (draining topsoil, higher temperatures and presence of a drought period during the summer). This work highlights the biological variability of $I$. montana related to the variation of its natural habitats which is promising for the future domestication of this plant. The manipulation of environmental factors during cultivation is of great interest due to its innovative perspective for modulating and exploiting the phytochemical production of I. montana.
\end{abstract}

\section{Introduction}

The sessile living strategy of terrestrial plants, anchored to the ground, forces them to face environmental variations. Plants have developed complex responses to modify their morpho-physiological characteristics to counteract both biotic and abiotic factors (Suzuki et al., 2014; Rouached et al., 2015). Altitude is described as an integrative environmental parameter that influences phytocoenoses in terms of species distribution, morphology and physiology (Liu et al., 2016). It reflects, at minimum, a mixed combination of temperature, humidity, solar radiation and soil type (Körner, 1999). In addition, the plant age, season, microorganism attacks, competition, soil texture and nutrient availability have been proven to strongly influence the morphology and the secondary metabolite profile of plants (Seigler, 1998). Altitudinal gradients are attractive for eco-physiological studies to decipher the mechanisms by which abiotic factors affect plant biological characteristics and how those factors influence species distribution (Graves and Taylor, 1988). For instance, a summer increase of nearly $10 \%$ in solar irradiance per $1000 \mathrm{~m}$ in elevation has been demonstrated in the European Alps. This increase was also characterized by an $18 \%$ increase in UV radiation (Blumthaler et al., 1997). Considering the reliefs of the Mediterranean basin, plants must confront both altitude and specific climate, namely high summer temperatures, infrequent but abundant precipitation, and wind (Bolle, 2012). Moreover, plants that live at higher elevation must also survive winter conditions characterized by low temperatures and high irradiance. All together, these factors force the plants to develop dedicated short- and long-term phenological, morphological and physiological adaptations (Kofidis et al., 2007). Many of these adjustments are protective mechanisms against photoinhibition of photosynthesis (Guidi and Calatayud, 2014; Sperlich et al., 2015), and most of them involve the synthesis of secondary metabolites (Ramakrishna and Ravishankar, 2011; Bartwal et al., 2012).

\footnotetext{
* Corresponding author at: Université d'Avignon, UMR QUALISUD, 301 rue Baruch de Spinoza, BP 21239/84916 AVIGNON Cedex 9, France.

E-mail address: david.roux@univ-avignon.fr (D. Roux).
} 
The genus Inula (Asteraceae) includes more than 100 species that are widely distributed in Africa and Asia and throughout the Mediterranean region. These plants have long been collected or cultivated around the world for their ethnomedicinal uses. They synthesize and accumulate significant amounts of specific terpenoids and flavonoids. Secondary metabolites (including sesquiterpene lactones) from Inula spp. have shown interesting biological activities such as antitumor, anti-inflammatory, antidiabetic, bactericidal, antimicrobial and antifungal activities, and these plants have also been used for tonics or diuretics (Reynaud and Lussignol, 1999; Seca et al., 2014).

The species Inula montana is a hairy rhizomatous perennial (hemicryptophyte) herb with a $10-40 \mathrm{~cm}$ circumference and solitary capitulum (5-8 cm diameter) of yellow florets (long ligules) positioned at the top of $\mathrm{a} \approx 20 \mathrm{~cm}$ floral stem. It grows at altitudes of $50-1300 \mathrm{~m}$ from eastern Italy to southern Portugal and is frequent in Southeast France. This calcicolous and xerophilous plant can be locally abundant, particularly in the Garrigue-type lands (Gonzalez Romero et al., 2001; Girerd and Roux, 2011; Tela Botanica, 2016). In the south of France, $I$. montana was incorrectly called "Arnica" because it was used in old traditional medicine as an alternative drug to the well-known Arnica montana (Reynaud and Lussignol, 1999). Due to herbivory pressure, loss of habitat and the fact that it is mainly harvested from the wild, $A$. montana is cited in the Red List of Threatened Species (IUCN). In Europe, more than $50 \mathrm{t}$ of dried flowers are traded each year (Sugier et al., 2013). Although many efforts are currently underway to domesticate A. montana and to correctly manage its habitats, the opportunity to find an alternative plant would therefore be of considerable interest.

In this context, we have developed a scientific program that aims to rehabilitate, domesticate and test $I$. montana as an efficient pharmaceutical substitute to A. montana. We have recently published a phytochemical investigation of the contents of leaves and flowers of $I$. montana (Garayev et al., 2017). Those data showed new compounds with associated anti-inflammatory activity. Here, we present the results of an ecophysiological study of $I$. montana that aimed to analyze the putative correlations between its morphology, its phytochemical production (with a focus on sesquiterpene lactones) and the characteristics (edaphic and climatic) of its natural habitats. It was expected that $I$. montana would face various abiotic stresses according to the large altitude gradient of its habitats. Assessing the response of the plant to its natural growing conditions will be helpful for its future domestication. In addition, a successful identification of environmental levers that could modulate the phytochemical production of this medicinal plant would be of great interest.

\section{Material and methods}

\subsection{Luberon park}

The present study was focused on I. montana populations growing in the French "Parc Naturel Régional du Luberon" (Luberon Park) that is located in southeastern France. The park (185,000 ha) is characterized by medium-sized mountains (from 110 to $1125 \mathrm{~m}$ high; mean altitude $\approx 680 \mathrm{~m}$ ) that stretch from west to east over the "Vaucluse" and the "Alpes-de-Haute-Provence" regions (Supplemental file). Although the overall plant coverage of Luberon Park belongs to the land type "Garrigue" (calcareous low scrubland ecoregion), there are two significant climatic influences: first, the north-facing shady side is characterized by a cold and humid climate that supports the development of deciduous species such as the dominant white oak (Quercus pubescens). Second, the sunny south-facing side receives eight to ten times more solar radiation. On this side, the vegetation is typically Mediterranean with a majority of green oak (Quercus ilex), Aleppo pine (Pinus halepensis), kermes oak (Quercus coccifera) and rosemary (Rosmarinus officinalis). The ridges of the Luberon Park suffer from extreme climatic variations: windy during all seasons, intense summer sun, cold during the winter, dry atmosphere and spontaneous and intense rains. These conditions limit the spectrum of plant species to those most resistant to these conditions, such as the common juniper (Juniperus communis) and boxwood (Buxus sp.) (Gressot, 2010).

\subsection{Sites of interest and sampling}

Inula montana is present in highly variable amounts over Luberon Park. By exploring the south-facing sides we selected three sites of interest: Murs, Bonnieux and Apt (Supplemental file). At these locations, I. montana forms several small, sparse and heterogeneous groups of tens of plants per hectare. These sites were also selected for their similar presentation as grassy clearings (area from 4 to 9 ha) and for their uniform flatness and slight inclination $(\approx 7 \%)$. The linear distance between the 3 sites is $21.4 \pm 2 \mathrm{~km}$. The Apt site is $500-600 \mathrm{~m}$ higher than both other sites. A preliminary phenological survey showed that the vegetative growth of $I$. montana extended from early April to late October, consistent with the hemicryptophytic strategy of the plant. Mid-June corresponded to the flowering period, which lasted $\approx 10$ days. Accordingly, samples were synchronously collected from the three habitats at four consecutive periods during 2014: early April (early spring), mid-May (late spring), mid-June (summer) and late October (autumn).

\subsection{Climatic and edaphic data}

The measurements of climate characteristics (standard weather stations, $1.5 \mathrm{~m}$ height above soil surface) were accessed from the French weather data provider (meteofrance.fr, 2014, France) and supplemented with agronomic weather station data near each site (climatedata.org, 2014, Germany). The satellite-based solar radiation measurements (Copernicus Atmosphere Monitoring Service (CAMS)) were obtained from the solar radiation data service (soda-pro.com, 2014, MINES ParisTech, France). The measurements of the physical properties of the soils and of the chemical content of the aqueous extracts (cf. Table 1) were subcontracted to an ISO certified laboratory (Teyssier, Bordeaux, France) according to standards. Briefly, $10 \mathrm{~g}$ of raw soil were milled, dried $\left(12 \mathrm{~h}\right.$ at $45^{\circ} \mathrm{C}$, except for nitrogen determination) and sifted ( $2 \mathrm{~mm}$ grid). Samples were then stirred into $50 \mathrm{ml}$ of demineralized water for $30 \mathrm{~min}$ at $20^{\circ} \mathrm{C}$ and filtered. Organic matter was measured after oxidation in potassium dichromate and sulfuric acid. $\mathrm{NH}_{4}$ and $\mathrm{NO}_{3}$ were extracted with $1 \mathrm{M} \mathrm{KCl}$. Organic matter, $\mathrm{NH}_{4}, \mathrm{NO}_{3}$ and water-extractable $\mathrm{PO}_{4}$ were then determined by colorimetric methods. $\mathrm{K}, \mathrm{Mg}, \mathrm{Ca}, \mathrm{Fe}, \mathrm{Cu}, \mathrm{Mn}, \mathrm{Zn}$ and Bo were determined by atomic absorption spectroscopy.

\subsection{Determination of growth parameters}

Plant growth for each period evaluated was determined by using several parameters: fresh and dry weight, water content, leaf area, and height of floral stem at the flowering stage. For each period, ten plants were collected randomly from each of the three sites (Luberon Park). The fresh weight was measured immediately after harvest, and the leaves were scanned to measure their area with the ImageJ software (National Institutes of Health, USA). The collected plants were subsequently dried $\left(80^{\circ} \mathrm{C}, 24 \mathrm{~h}\right)$ to calculate the water content. Glandular trichome density was assessed on 10 leaves randomly collected at the flowering period from 10 different plants per site. This assessment was performed using a stereomicroscope (Nikon ZX 100, Canagawa, Japan) equipped with fluorescence (excitation $382 \mathrm{~nm}$, emission $536 \mathrm{~nm}$ ) and digital camera (Leica DFC 300 FX, Wetzlar, Germany). The captured images allowed the quantification of glandular trichomes using ImageJ.

\subsection{Chlorophyll-a fluorescence measurements}

Chlorophyll-a fluorescence was measured in vivo using a portable 
Table 1

Pedoclimatic characterization of Inula montana habitats. Exp. $\Delta$ : expected theoretical range of element concentrations for a standard agricultural parcel.

\begin{tabular}{|c|c|c|c|c|}
\hline \multicolumn{5}{|c|}{ Climate } \\
\hline \multicolumn{2}{|c|}{ Mean temperature $\left({ }^{\circ} \mathrm{C}\right)$} & 11.0 & 12.1 & 7.7 \\
\hline \multicolumn{2}{|c|}{ Air moisture (\%) } & 66.5 & 69.7 & 54.4 \\
\hline \multicolumn{2}{|c|}{ Annual precipitation (mm) } & 774 & 702 & 928 \\
\hline \multicolumn{5}{|c|}{ Topsoil } \\
\hline \multicolumn{2}{|c|}{ Composition (\%) \& texture } & Sandy loam & $\begin{array}{l}\text { Sandy clayey } \\
\text { loam }\end{array}$ & Clayey loam \\
\hline \multicolumn{2}{|c|}{$\begin{array}{l}\text { Organic matter (from aqueous } \\
\text { extract) }\end{array}$} & 5.01 & 4.98 & 5.00 \\
\hline \multicolumn{2}{|c|}{ Clay } & 6.4 & 16.1 & 18.0 \\
\hline \multicolumn{2}{|l|}{ Sand } & 37.3 & 20.4 & 3.1 \\
\hline \multicolumn{2}{|l|}{ Silt } & 56.3 & 63.5 & 78.8 \\
\hline \multicolumn{4}{|c|}{ Macro- and microelements (mg/kg from aqueous extract) } & $\operatorname{Exp} . \Delta$ \\
\hline $\mathrm{pH}$ & 8.3 & 7.8 & 7.7 & \\
\hline $\mathrm{NH}_{4}$ & 3.96 & 2.56 & 2.09 & $4.0-8.0$ \\
\hline $\mathrm{NO}_{3}$ & 3.79 & 3.14 & 1.29 & $4.0-8.0$ \\
\hline $\mathrm{K}$ & 5.4 & 5.4 & 2.7 & $40-80$ \\
\hline $\mathrm{PO}_{4}$ & 0.2 & 0.2 & 0.2 & $15-25$ \\
\hline $\mathrm{Mg}$ & 2.5 & 2.5 & 3.3 & $20-40$ \\
\hline $\mathrm{Ca}$ & 96.2 & 71.8 & 68.7 & $100-200$ \\
\hline $\mathrm{Fe}$ & 0.33 & 0.07 & 0.14 & $8.0-12.0$ \\
\hline $\mathrm{Cu}$ & 0.01 & 0.01 & 0.01 & $0.30-0.50$ \\
\hline Mn & 0.13 & 0.14 & 0.08 & $0.30-0.50$ \\
\hline $\mathrm{Zn}$ & 0.09 & 0.08 & 0.07 & $0.30-0.50$ \\
\hline Bo & 0.51 & 0.49 & 0.53 & $1.0-2.0$ \\
\hline
\end{tabular}

Handy-PEA meter (Hansatech, Kings Lynn, UK) on 20 plants arbitrarily selected three times per day: in the morning (10:00), at midday (12:00) and in the afternoon (14:00). This was done for each considered time period (season) and for each of the three I. montana habitats. The fluorescence parameters calculated were the maximum quantum yield of primary photosystem II photochemistry $(\mathrm{Fv} / \mathrm{Fm})$ and the performance index (PI) according to the OJIP test (Strasser et al., 2000). Both parameters are plant stress indicators and provide indications of the overall plant fitness. The ratio $(\mathrm{Fv} / \mathrm{Fm})$ between variable chlorophyll fluorescence $(\mathrm{Fv}=\mathrm{Fm}-\mathrm{F} 0)$ and maximum fluorescence $(\mathrm{Fm})$ is the most used parameter to assess plant stress. Initial fluorescence (F0) is obtained from dark adapted samples and maximum fluorescence $(\mathrm{Fm})$ is measured under a saturation pulse (Maxwell and Johnson, 2000; Rohaçek, 2002). PI is an integrative parameter that reflects the contribution to photosynthesis of the density of reaction centers and both the light and the dark reactions (Poiroux-Gonord et al., 2013). All of the parameters were calculated from the measured fluorescence of leaves under saturating pulsed light $\left(1 \mathrm{~s}\right.$ at $\left.3500 \mu \mathrm{mol} \mathrm{m} \mathrm{m}^{-2} \mathrm{~s}^{-1}\right)$ after $20 \mathrm{~min}$ adaptation to the dark.

\subsection{Total polyphenol and flavonoid contents}

Harvested leaves were air dried on absorbent paper at room temperature for 3 weeks. The samples were prepared by maceration at room temperature for $96 \mathrm{~h}$ in $20 \mathrm{ml}$ of $50 \%$ ethanol (v/v) (Carlo Erba, Italy). This step was followed by ultrasonic extraction for $30 \mathrm{~min}$. The samples were then filtered into a $20 \mathrm{ml}$ volumetric flask and adjusted to volume with the same solvent. The total polyphenol content was determined according to paragraph 2.8.14 of the current European Pharmacopoeia (Ph. Eur, 2017): the absorbance was measured at $760 \mathrm{~nm}$ (Shimadzu 1650pc, Japan), and the results are expressed as pyrogallol (Riedel-de-Haën, Germany) equivalents in percent $(\mathrm{g} / 100 \mathrm{~g}$ of dried plant sample). The total flavonoid content was determined according to the aluminum chloride colorimetric method of monograph number 2386 (safflower flower) from the current European Pharmacopoeia. The absorbance was measured at $396 \mathrm{~nm}$ (Shimadzu 1650pc), and the results are expressed as the percentage of total flavonoids relative to luteoline $\left(\mathrm{C}_{15} \mathrm{H}_{10} \mathrm{O}_{6} ; \mathrm{Mr} 286.2\right)$.

\subsection{High-performance liquid chromatography (HPLC) analyses}

The extraction was performed by mixing $10 \mathrm{~g}$ of dried leaves with $100 \mathrm{ml}$ of $\mathrm{CH}_{2} \mathrm{Cl}_{2}$ (Carlo Erba, Italy) and introducing the mixture into a glass column in order to extract compounds by percolation with dichloromethane. After $18 \mathrm{~h}$ of maceration, $100 \mathrm{ml}$ of dichloromethane extract was collected and evaporated to dryness. Next, $10 \mathrm{mg}$ of dried extract were dissolved in $5 \mathrm{ml}$ of methanol (Carlo Erba) and centrifuged. Then, $4 \mathrm{ml}$ of the supernatant was brought to a final volume of $10 \mathrm{ml}$ with distilled water. The solution was filtered through a $0.45-\mu \mathrm{m}$ membrane. The analyses were performed using an Agilent 1200 series apparatus (G1379A degasser, G1313A autosampler, G1311A quaternary pump, G1316A column thermostat and G1315 B diode array detector (DAD)) (Agilent, Germany) with a Luna C18 adsorbent ( $3 \mu \mathrm{m}$, $150 \mathrm{~mm} \times 4.6 \mathrm{~mm}$ ) (Phenomenex, USA) and a SecurityGuard C18 column ( $3 \mathrm{~mm}$ ID $\times 4 \mathrm{~mm}$ cartridge) (Phenomenex). Instrument control, data acquisition and calculation were performed with ChemStation B.02.01. (Agilent). The mobile phase consisted of 52\% $\mathrm{MeOH}$ (Carlo Erba) and $48 \%$ water (Millipore, Germany), and the $\mathrm{pH}$ of the mobile phase was 5.5 . The flow rate was $1.0 \mathrm{ml} / \mathrm{min}$. The detector was operated at $210 \mathrm{~nm}$ (sesquiterpene lactones absorption wavelength), and peaks were identified according to Garayev et al. (2017). The injection volume was $20 \mu l$.

\subsection{Statistical analysis}

The principal component analysis (PCA) and non-parametric test were performed using $\mathrm{R}$ ( $\mathrm{R}$ Foundation, Austria). For multiple comparisons, the post hoc Kruskal-Wallis-Dunn test with the Bonferroni adjustment method was used. The $\mathrm{R}$ libraries used were factomineR, PMCMR, and multcompView. The data are displayed as the means \pm standard error of the mean and were considered significant at $\mathrm{p}<0.05$.

\section{Results}

\subsection{Pedoclimatic characterization of I. montana habitats}

Among the three Luberon Park sites assessed, Murs and Bonnieux showed a similar climatic pattern in terms of temperature and precipitation (Fig. 1). In addition, the 20 -year-data suggested that both of these I. montana habitats experienced a drought period centered on July (1-2 months long). The Apt habitat, which is 500-600 m higher than the two other sites (Supplemental file), showed a lower mean temperature and higher precipitation. In addition, Apt notably displayed the absence of a drought period, according to the averaged data (Fig. 1), but it showed drier air throughout the year (Table 1).

The 3-year (2013-2015) satellite-based measurement of the global solar irradiation on the horizontal plane at ground level (GHI) (Fig. 2) showed a strong increase in irradiance from January to June, a stable amount of radiation from June to July and then a strong decrease until December. When investigating the irradiance in detail for the $3 \mathrm{I}$. montana populations, no difference was observed (GHI). However, when irradiance was estimated under clear sky, namely by virtually removing the clouds (Clear-Sky GHI), it appeared that the Apt site received $\approx 3 \%$ higher solar irradiation from May to July. Taken together, these results indicate that the cloudier Apt weather compensates on average for the higher solar irradiation at this altitude.

Considering the physical characteristics of the topsoil, Apt appeared clayey and loamy, whereas Murs and Bonnieux were much richer (6-12 

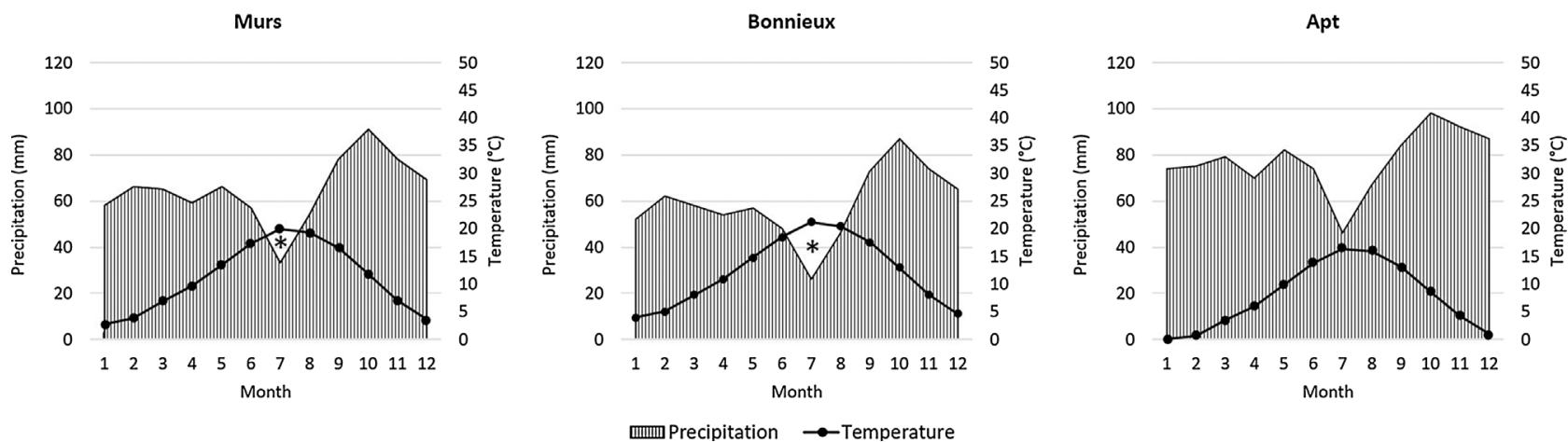

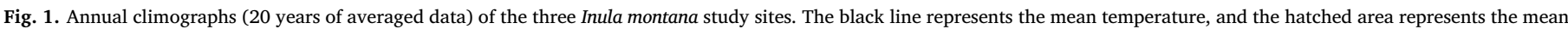
precipitation per month (rainfall or snow). Drought periods are symbolized by an asterisk.

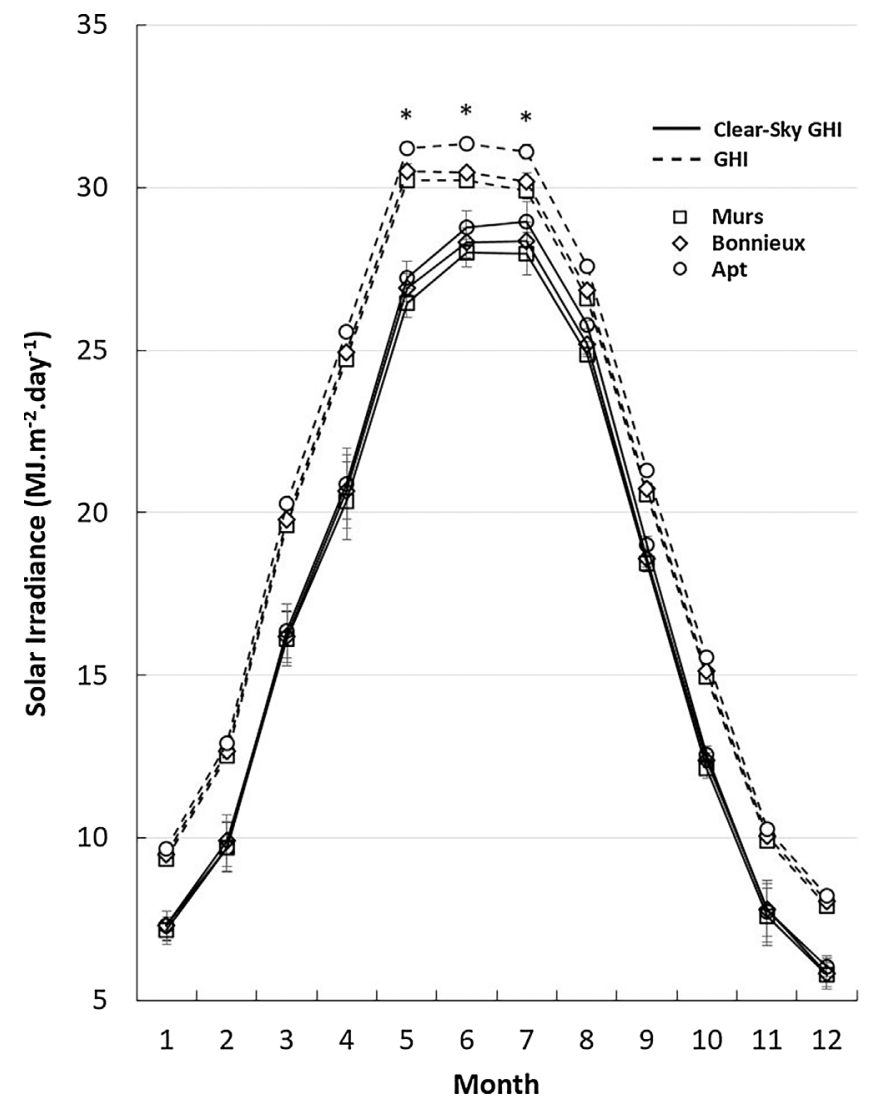

Fig. 2. Monthly means of satellite-based global solar irradiation as measured on the horizontal plane at ground level (GHI). The solid lines (GHI) represent the actual terrestrial solar radiation; the dashed lines (Clear-Sky GHI) estimate the irradiation under a cloudless sky. The data represent the means of 3 years of records (2013-2015) for the 3 Inula montana populations (spatial resolution was $3-8 \mathrm{~km}$ ). The asterisks indicate significant differences between sites at $\mathrm{p}<0.05$.

times) in sand (Table 1). Concerning the chemical characteristics, the analysis of the topsoil aqueous extracts showed that all three growing sites appeared equally poor (Table 1 ). The Apt topsoil showed slightly lower levels of $\mathrm{NH}_{4}, \mathrm{NO}_{3}, \mathrm{~K}, \mathrm{Ca}, \mathrm{Mn}$ and $\mathrm{Zn}$ than either of the other sites and also showed the lowest $\mathrm{pH}$.

\subsection{Impact of the geographic location and seasonal progress on I. montana morphology and physiology}

Until autumn, I. montana plants from the Apt population showed less leaf blade surface area than leaves from the other sites (Fig. 3A). All three habitats displayed an intensive early-spring growth period, but during late spring, the leaf surface area was $45 \%$ lower at the Apt site than at the other sites. However, at Apt, the leaf area was quite stable after this time and for the remaining period, but the leaf surface decreased progressively from late spring to autumn at the two lower-altitude sites (Murs and Bonnieux). There was no significant variation in the number of leaves during the season, with the exception of a slight difference during summer between Bonnieux and the two other habitats (Fig. 3B).

In addition, the geographic location of I. montana habitats seemed to influence both the length of the flowering stem and the number of glandular trichomes per leaf (Table 2). It appeared that I. montana plants from the Apt habitat showed a significantly shortened floral stem $(\approx-12 \%)$ and fewer leaf glandular trichomes $(\approx-23 \%)$ in comparison with the other sites (Murs and Bonnieux).

Dry and fresh weights increased from spring to summer and then decreased until autumn (Fig. 4A, B). When comparing the three $I$. montana habitats in terms of plant dry weight, they showed no difference during the overall season (Fig. 4A). Similarly, all plants showed essentially the same water content until late spring (Fig. 4C). Then, Apt plants displayed a water content of over $70 \%$ during the remaining seasons, while plants from the two low-elevation locations stayed below 65\% (Bonnieux showed the lowest value in the summer: 55\%).

Both indicators from chlorophyll a fluorescence measurements (the maximum quantum yield of primary photosystem II photochemistry and the performance index) showed slight decreases during the summer regardless of the geographic location of the plants (Fig. 5). The overall values then increased until autumn, but they did not return to their initial levels. In addition, I. montana plants from the Apt population showed higher Fv/Fm and PI values during the whole growing period than did plants in the two low-altitude habitats.

\subsection{Phytochemical contents of I. montana according to geographic location}

The amounts of total polyphenols and their flavonoid subclass during the overall period did not differ among the three habitats, with the exception of a lower level of polyphenols during late-spring for the plants in Bonnieux (Fig. 6A). For the three habitats, the total polyphenol level was $49 \%$ lower in autumn than in the early spring. The total flavonoids (Fig. 6B) showed an average increase of $56 \%$ from early spring to summer (higher level) but then decreased drastically thereafter $(-68 \%)$.

We conducted high-performance liquid chromatography analysis on the leaves of the I. montana plants. The chromatograms (Fig. 7) showed 10 major peaks, in which we recently identified (by the external standard method) 5 sesquiterpene lactones (Garayev et al., 2017) respectively artemorin (p1), 9B-hydroxycostunolide (p2), reynosin (p3), santamarine ( $\mathrm{p} 5$ ) and costunolide (p10). Other peaks were determined to be a mix of two flavonoids (Chrysosplenol C and 6-hydroxykaempferol 3,7-dimethyl ether; p4) and four inositol derivatives (myoinositol-1,5- 
A

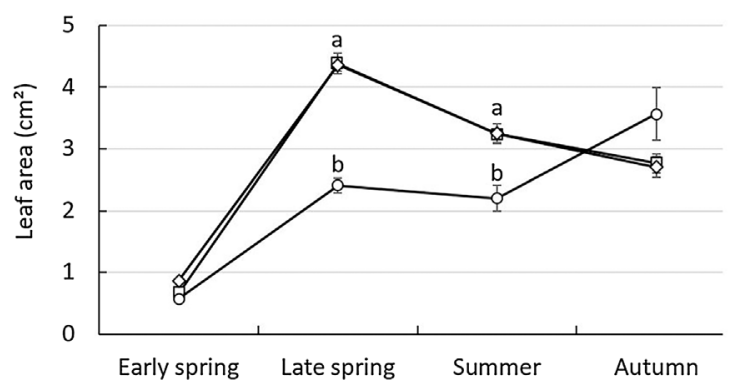

B

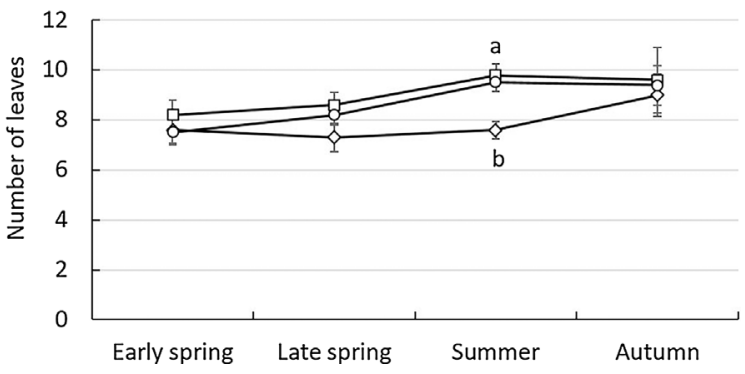

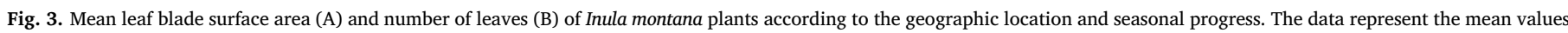
of 10 plants \pm standard error. The lowercase letters represent significant differences at $\mathrm{p}<0.05$.

Table 2

Impact of the geographic location on Inula montana morphology at the flowering stage. The data represent the mean values of 10 plants \pm standard error. The lowercase letters represent significant differences at $\mathrm{p}<0.05$.

\begin{tabular}{lll}
\hline $\begin{array}{l}\text { I. montana } \\
\text { habitats }\end{array}$ & Floral stem length $(\mathrm{cm})$ & $\begin{array}{l}\text { Glandular trichomes per leaf area } \\
\left(0.60 \mathrm{~mm}^{2}\right)\end{array}$ \\
\hline Murs & $22.72 \pm 0.58 \mathrm{a}$ & $19.25 \pm 1.33 \mathrm{a}$ \\
Bonnieux & $21.91 \pm 0.41 \mathrm{a}$ & $18.52 \pm 1.40 \mathrm{a}$ \\
Apt & $20.06 \pm 0.36 \mathrm{~b}$ & $14.75 \pm 0.56 \mathrm{~b}$ \\
\hline
\end{tabular}

diangelate-4,6-diacetate, myoinositol-1,6-diangelate-4,5-diacetate, myoinositol-1-angelate-4,5-diacetate-6-(2-methylbutyrate), myoinositol-1-angelate-4,5-diacetate-6-isovalerate; $\mathrm{p} 6$ to p9). The cross-location and cross-time relative quantification of the 5 sesquiterpene lactones (Table 3) suggested that I. montana plants from the low-altitude Murs and Bonnieux populations contained approximately three times more phytochemicals than plants from Apt. The data also showed that p1, p3 and p5 tended to accumulate throughout the seasons, unlike p2 and p10, which decreased. Lastly, p10 appeared to be the most abundant compound (roughly 50\% more than the other lactones) regardless of the location or season.

\section{Discussion}

\subsection{Inula montana morphology}

montana plants exhibited shorter floral stem length and reduced leaf surface at high altitude (Apt; Table 2 and Fig. 3A). This is consistent with the tendency of many plants to shorten their organs during winter (Åström et al., 2015) or at high elevation due to low temperatures and strong wind speeds, as shown previously in three Asteraceae species (Yuliani et al., 2015). This behavior allows for limiting dehydration and ameliorate the photosynthetic conditions by setting plant organs closer to the warmer soil surface (Cabrera et al., 1998). The seasonal modification of the leaf morphology has also been shown to optimize photosynthetic capacity (Åström et al., 2015). The slightly lower nutrient availability at Apt (Table 1) may also contribute to the smaller organ sizes. In addition, the leaf surface of $I$. montana remained stable during the hot period at Apt, whereas it decreased at low altitude (Fig. 3B). This result is correlated with both the higher temperature and the drought period present at the low-elevation sites. Taken together, the data suggest that the plant morphological response is clearly adapted to both the climate and the location.

Inula montana displays two different trichome types on its leaves: hairy and glandular. Trichomes are well described as being plastic and efficient plant weapons against herbivory, notably through their high contents of protective secondary metabolites. Insect feeding can modify both the density and the content of trichomes (Tian et al., 2012). Abiotic factors also strongly influence plant hairs; for example dry conditions, high temperatures or high irradiation can increase the number of trichomes per unit leaf area (Pérez-Estrada et al., 2000). Conversely, trichome density decreases in the shade or in well-irrigated plants. In this context, water availability in the plant environment is an integrative factor (Picotte et al., 2007). Our data are consistent with this model, since plants from the Apt habitat (showing the highest altitude and precipitation but the lowest temperatures) displayed fewer glandular trichomes on their leaves than either of the other growing sites that suffered from drought periods (Table 2). These results also indicate that $I$. montana undergoes a stronger or at least a different type of stress at low altitude.

\subsection{Inula montana physiology}

It appeared that I. montana biomass increased from early spring to summer but then decreased, consistent with the hemicryptophytic strategy of this plant (dry weight, Fig. 4A). The location of the $I$. montana habitats had no effect on the dry weight but significantly influenced the plant water content, which markedly decreased during the summer at low elevation (Murs and Bonnieux; Fig. 4C). This is consistent with the expectation that low-elevation regions in the Mediterranean area would be hotter and drier than high-altitude regions,
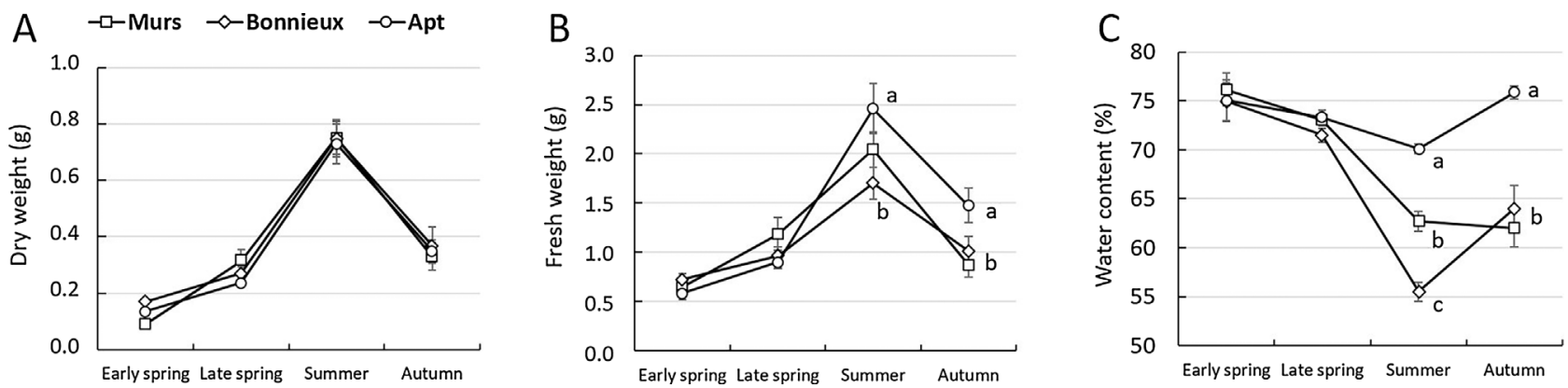

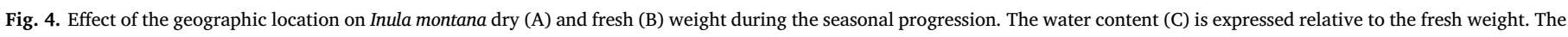
data represent the mean values of 10 plants \pm standard error. The lowercase letters represent significant differences at $\mathrm{p}<0.05$. 
A $\quad-\square-$ Murs $\multimap$ Bonnieux $-\infty$-Apt

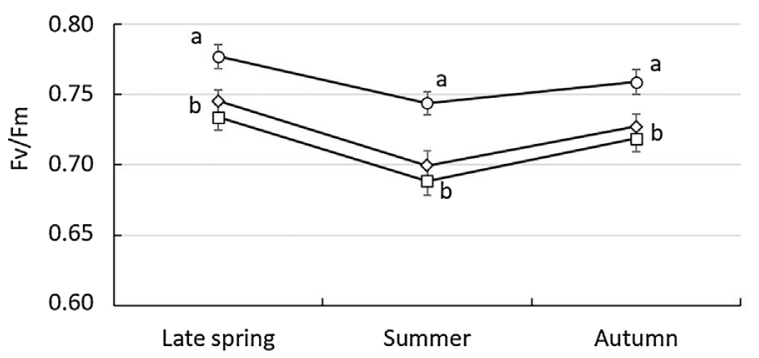

B

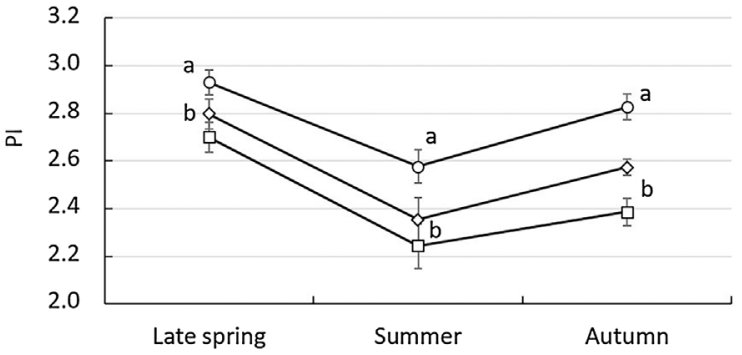

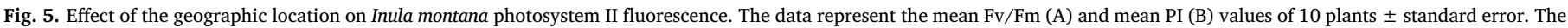
lowercase letters represent significant differences at $\mathrm{p}<0.05$.
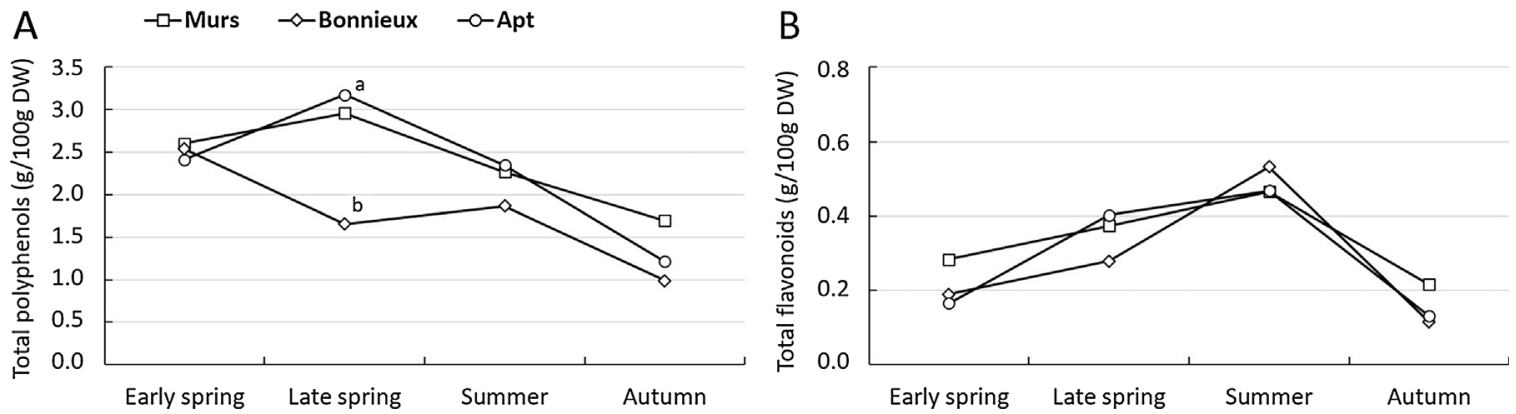

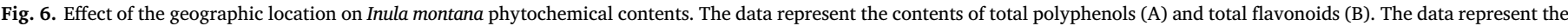
mean values of 10 plants \pm standard error. The lowercase letters represent significant differences at $\mathrm{p}<0.05$.

leading to more stressful conditions for plants (Kofidis et al., 2007; Wolfe and Tonsor, 2014). The absence of an effect on the dry weight of I. montana here illustrates the strong variability of this xerophilous plant, namely its capacity to grow in various habitats and its ability to resist drought.

Chlorophyll a fluorescence has been described as an accurate indicator of the plant response to environmental fluctuations and biotic stress (Murchie and Lawson, 2013; Guidi and Calatayud, 2014) and has gained interest in ecophysiological studies (Åström et al., 2015; PereraCastro et al., 2017). The maximum photochemical quantum yield of PSII (Fv/Fm) and the performance index (PI) reflect photooxidative stress and plant fitness (Strasser et al., 2000). Fv/Fm values usually vary from 0.75 to 0.85 for non-stressed plants. Any decrease indicates a stressful situation, reducing the photosynthetic potential (Maxwell and Johnson, 2000). In the Mediterranean climate, plant photoinhibition frequently occurs (Guidi and Calatayud, 2014). Below a certain limit of solar radiation, this protective mechanism allows the dissipation of excessive photosynthetic energy as heat (dos Santos et al., 2013). Here, both of the indicators (Fv/Fm and PI) displayed lower values at the lowelevation sites (Murs and Bonnieux; Fig. 5), confirming that I. montana was subjected to greater stress there. These results are in agreement with the observed drought periods at those sites and reflect the adaptive response of the plants to avoid photodamage under high temperature and drought stress in order to preserve their photosynthetic apparatus (Poiroux-Gonord et al., 2013). It is not possible to easily correlate these results to the solar radiation because no difference was observed among the 3 habitats, as described above (Fig. 2). However, a similar study that focused on the combined effects of altitude and season on Clinopodium vulgare highlighted a decrease in $\mathrm{Fv} / \mathrm{Fm}$ values in lowland populations at the beginning of a drought period (Kofidis et al., 2007).

\subsection{Secondary metabolites}

Plant secondary metabolites are well known for accumulating in response to environmental conditions that induce oxidative stress. Many studies have proposed that polyphenols might play a protective anti-oxidative role in plants (Bartwal et al., 2012; Bautista et al., 2015). Consequently, phenolics and other secondary metabolites usually accumulate under drought stress, salt stress (Adnan et al., 2016), high or low temperatures and at high altitude; this is exacerbated in Mediterranean plants (Kofidis et al., 2007; Scognamiglio et al., 2015). Phenology and plant development also strongly influence the concentrations of phenolic compounds (Radušienè et al., 2013). Our data showed that the I. montana leaf total polyphenol and flavonoid contents both varied over the season and reached their maximum value during latespring and summer (Fig. 6). This physiological behavior follows the seasonal solar radiation profile (Fig. 2) and is consistent with the welldescribed photoprotective role of polyphenols (Agati and Tattini, 2010). It has long been known that the quantity of solar radiation increases with altitude (Spitaler et al., 2006). Accordingly, we expected a higher content of phenolics at high elevation due to the higher irradiance, including UV. However, the cloudier weather at the Apt site appeared to compensate for the theoretical 3\% difference in sunshine between that site and the 2 other I. montana habitats (Fig. 2). As such, our results cannot explain the low polyphenol content observed in latespring at Bonnieux. Either way, it appears that the stress perceived by $I$. montana plants at low altitude is not due to the simple variation in solar radiation but rather to a significant susceptibility to drought stress and/ or high temperatures.

Sesquiterpenes are an important group of organic compounds released by plants and are characteristic of the family Asteraceae. Most of them are volatile molecules used as hormones and for functions such as communication and defense against herbivory (Rodriguez-Saona et al., 2013; Chadwick et al., 2013). In this work we have identified 5 sesquiterpene lactones that tend to accumulate in higher amounts in lowelevation habitats (Table 3). These compounds also showed quantities that were positively or negatively correlated with the seasonal progression. Sesquiterpene lactones are well described to follow a seasonal pattern and to accumulate in response to biotic and abiotic stresses (Chadwick et al., 2013; Sampaio et al., 2016). Since these compounds play essential roles in the plant defense response, their accumulation under abiotic stress is consistent with the carbon balance theory, which 


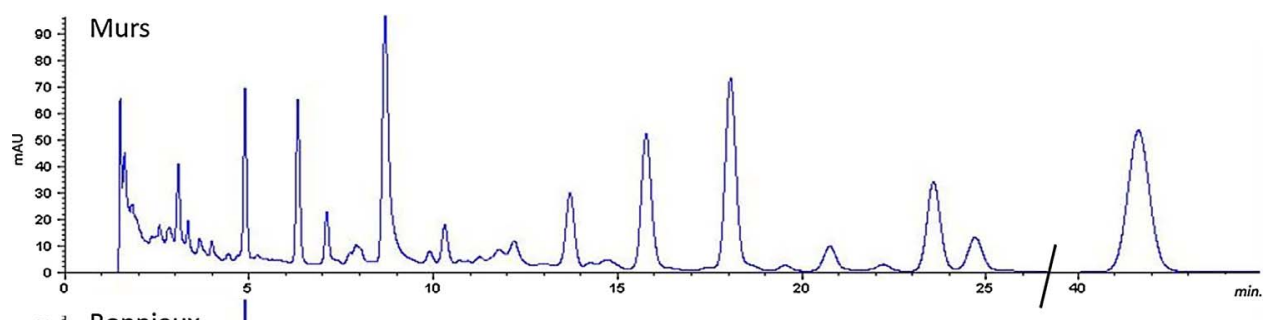

Fig. 7. HPLC chromatograms of Inula montana leaves harvested during the summer, according to the plant geographic location. S.l.: sesquiterpene lactone; Fl.: flavonoid; In.: inositol. Peaks were identified according to Garayev et al. (2017).
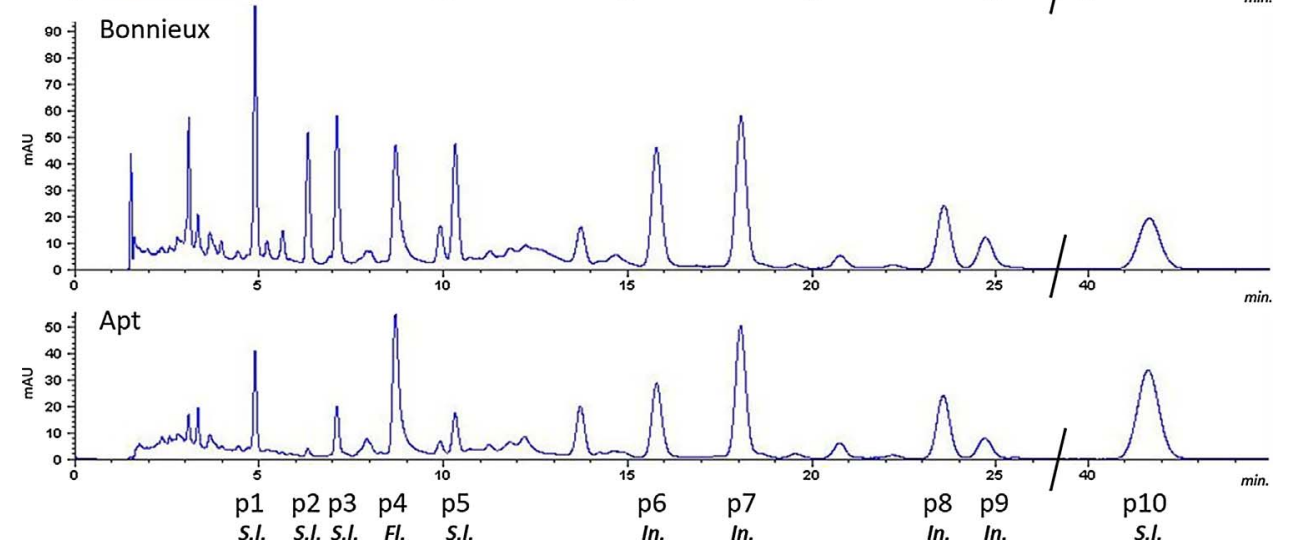

Table 3

Cross-location and cross-time relative quantification of the 5 sesquiterpene lactones found in Inula montana leaves. "-" indicates the absence of the molecule, and "+ ", "+ +", and " +++ " indicate its relative increasing abundance.

\begin{tabular}{|c|c|c|c|c|c|c|c|c|c|}
\hline & \multicolumn{3}{|c|}{ Early spring } & \multicolumn{3}{|c|}{ Late spring } & \multicolumn{3}{|c|}{ Summer } \\
\hline & Murs & Bonnieux & Apt & Murs & Bonnieux & Apt & Murs & Bonnieux & Apt \\
\hline p1 & - & - & - & + & + & - & ++ & +++ & + \\
\hline $\mathrm{p} 2$ & +++ & + & - & ++ & + & - & + & + & - \\
\hline p3 & - & - & - & + & + & - & + & +++ & + \\
\hline p5 & + & + & - & + & + & - & + & +++ & + \\
\hline p10 & ++ & +++ & + & +++ & +++ & + & + & + & + \\
\hline
\end{tabular}

states that the investment in plant defense increases in response to a growth limitation (Mooney, 1991). However, in Arnica montana, no positive correlation between the production of these molecules and altitude was found (Spitaler et al., 2006). In addition, plant terpenoid release has been reported to be modulated by temperature, drought and UV radiation (Loreto and Schnitzler, 2010).

The topsoil at the low altitude sites (Murs and Bonnieux) was significantly richer in sand than that at Apt (Table 1). This confers a high draining capacity to the low-elevation sites that would inevitably increase the water deficiency and contribute to the drought stress perceived by the plants. Last, our data from aqueous extracts highlighted a slightly lower topsoil nutrient content at the Apt site (Table 1). Although the literature on this topic is scarce, and no information is available concerning $\mathrm{N}$ and $\mathrm{K}$, some soil nutrients (namely $\mathrm{P}, \mathrm{Cu}$ and $\mathrm{Ca}$ ) can influence the plant sesquiterpene lactone content (Foster et al., 2006; Sampaio et al., 2016). More broadly, deficiencies in nitrogen have been described to induce the accumulation of plant phenylpropanoids (Ramakrishna and Ravishankar, 2011). Apt also showed the lowest Ca content and pH. Although the values were only slightly higher at the two other sites, they may globally contribute to decreasing the availability of topsoil cations. We cannot exclude the possibility that this would also contribute to the stress on the plants at these locations, but it is not easy to make a connection with the plant phytochemical production.

\section{Conclusion}

The morpho-physiological characteristics of I. montana showed that the plant undergoes higher stress at its lower-altitude growing sites (Murs and Bonnieux). Four plant and environmental variables (chlorophyll fluorescence, plant water content, climate and topsoil draining capacity) specially converged to highlight the site water availability as the primary source of stress. In addition, the sesquiterpene lactone production by $I$. montana was higher at these low-elevation stress-inducing habitats.

The overall data are summarized in the principal component analysis (Fig. 8). The I. montana growing location (dimension 1) and the seasons (dimension 2) encompass more than $76 \%$ of the total variability, and the location itself exceeds $50 \%$. The map confirms that plant stress (expressed as water content or $\mathrm{Fv} / \mathrm{Fm}$ ) and the subsequent release of sesquiterpene lactones (including 4 of the 5 compounds) are correlated to the integrative altitude parameter. The individual factor map (B) clearly discriminates the I. montana growing locations from the seasons and highlights the interaction of these two factors.

Dissecting the manner in which molecules of interest fluctuate in plants (in response to biotic and abiotic stress) is of great interest scientifically and economically (Pavarini et al., 2012). The present study shows that growing habitats that induce plant stress, particularly drought stress, can significantly enhance the production of sesquiterpene lactones by I. montana. Similar approaches have been conducted with A. montana (Spitaler et al., 2006; Perry et al., 2009; Clauser et al., 2014) and have provided valuable information and cultivation guidelines that helped with its domestication (Jurkiewicz et al., 2010; Sugier et al., 2013). Appropriate cultivation techniques driven by the ecophysiological study of $A$. montana have succeeded in influencing its sesquiterpene lactone content for medicinal use (Todorova et al., 2016). The manipulation of environmental stress has also been described to significantly promote the phytochemical (phenolic) content of lettuce (Oh et al., 2009) and halophytes (Slama et al., 2015; Adnan et al., 2016). Literature regarding I. montana is very sparse. The present results bode well for our ongoing field-work that aims to simulate and test environmental levers to augment the secondary metabolism and to develop innovative culture methods for I. montana.

Our data also illustrate the high morpho-physiological variability of this calcicolous plant. High-altitude habitat appears to primarly impact the morphology of the plant, while low-elevation sites mostly induce physiological responses to stress (chlorophyll fluorescence, phytochemicals synthesis). I. montana appears to grow well on south-facing sites possessing poor topsoil and low nutrient availability. It is also able to face high temperature and altitude gradients and to grow well on draining soil under a climate that induces drought stress. 

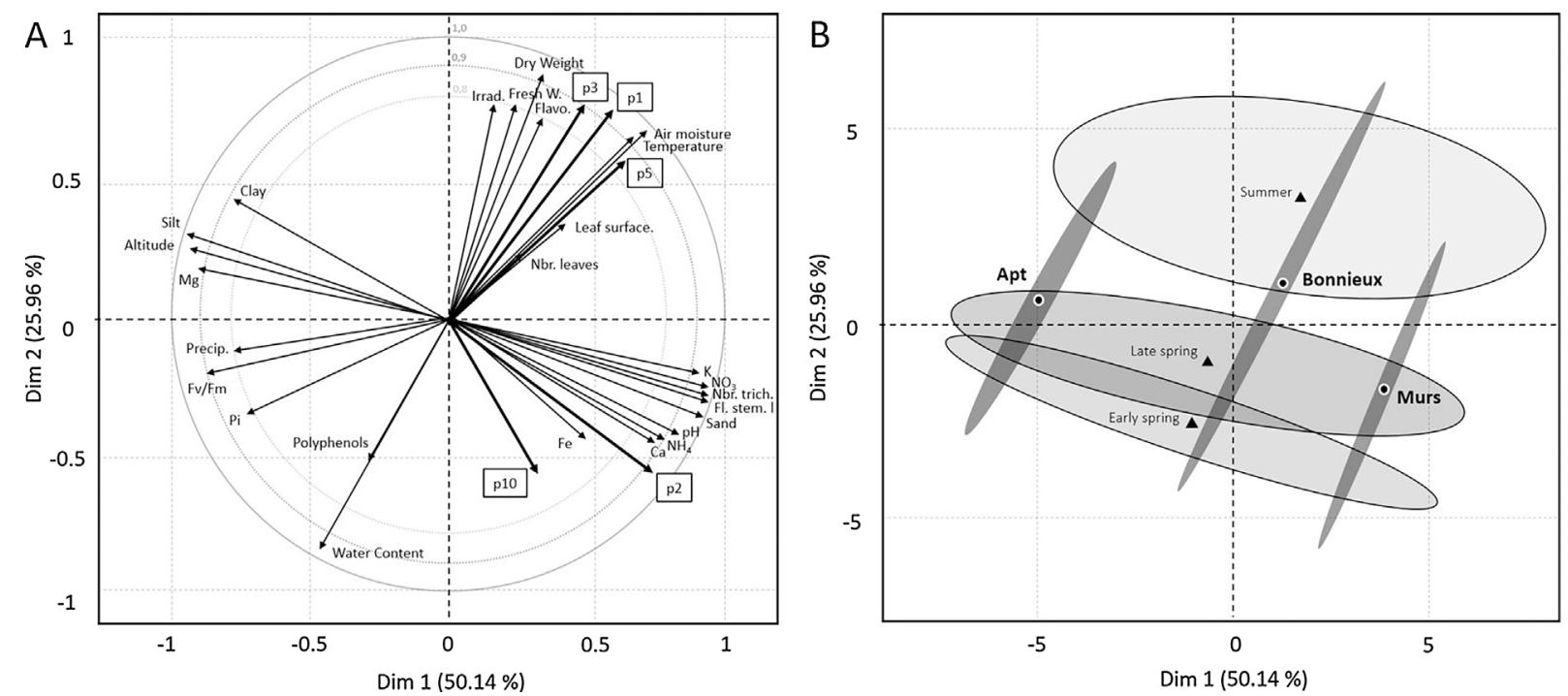

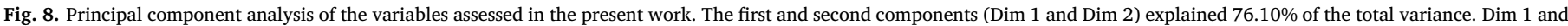

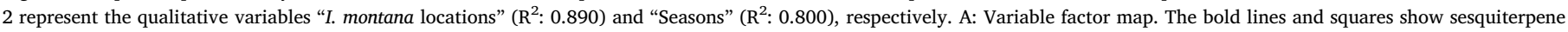
lactones; B: Individual factor map with confidence ellipses (95\%) around the descriptive variables.

\section{Acknowledgments}

This work was supported by the French region Provence-Alpes-Côte d'Azur (project $n^{\circ}$ 2013_13403), the Luberon Regional Natural Park and the TERSYS Research Federation of the University of Avignon. We thank Prof. Vincent Valles (Avignon University) for his advice on the statistics. We thank Didier Morisot, collections manager of the plant garden of the Faculty of Medicine of the University of Montpellier, for the I. montana identification.

\section{References}

Åström, H., Metsovuori, E., Saarinen, T., Lundell, R., Hänninen, H., 2015. Morphological characteristics and photosynthetic capacity of Fragaria vesca L. winter and summer leaves. Flora - Morphol. Distrib. Funct. Ecol. Plants 215, 33-39.

Adnan, M.Y., Hussain, T., Asrar, H., Hameed, A., Gul, B., Nielsen, B.L., Khan, M.A., 2016. Desmostachya bipinnata manages photosynthesis and oxidative stress at moderate salinity. Flora - Morphol. Distrib. Funct. Ecol. Plants 225, 1-9.

Agati, G., Tattini, M., 2010. Multiple functional roles of flavonoids in photoprotection. New Phytol. 186, 786-793.

Bartwal, A., Mall, R., Lohani, P., Guru, S.K., Arora, S., 2012. Role of secondary metabolites and brassinosteroids in plant defense against environmental stresses. J. Plant Growth Regul. 32, 216-232.

Bautista, I., Boscaiu, M., Lidón, A., Llinares, J.V., Lull, C., Donat, M.P., Mayoral, O., Vicente, O., 2015. Environmentally induced changes in antioxidant phenolic compounds levels in wild plants. Acta Physiol. Plant. 38, 9.

Blumthaler, M., Ambach, W., Ellinger, R., 1997. Increase in solar UV radiation with altitude. J. Photochem. Photobiol. B 39, 130-134.

Bolle, H.-J., 2012. Mediterranean Climate: Variability and Trends. Springer Science \& Business Media, New York.

Cabrera, H.M., Rada, F., Cavieres, L., 1998. Effects of temperature on photosynthesis of two morphologically contrasting plant species along an altitudinal gradient in the tropical high Andes. Oecologia 114, 145-152.

Chadwick, M., Trewin, H., Gawthrop, F., Wagstaff, C., 2013. Sesquiterpenoids lactones: benefits to plants and people. Int. J. Mol. Sci. 14, 12780-12805.

Clauser, M., Aiello, N., Scartezzini, F., Innocenti, G., Dall'Acqua, S., 2014. Differences in the chemical composition of Arnica montana flowers from wild populations of north Italy. Nat. Prod. Commun. 9, 3-6.

dos Santos, C.M., Verissimo, V., Wanderley Filho, H.C., de, L., Ferreira, V.M., Cavalcante, P.G., da, S., Rolim, E.V., Endres, L., 2013. Seasonal variations of photosynthesis gas exchange, quantum efficiency of photosystem II and biochemical responses of Jatropha curcas L. grown in semi-humid and semi-arid areas subject to water stress. Ind. Crops Prod. 41, 203-213.

Foster, J.G., Clapham, W.M., Belesky, D.P., Labreveux, M., Hall, M.H., Sanderson, M.A.,
2006. Influence of cultivation site on sesquiterpene lactone composition of forage chicory (Cichorium intybus L.). J. Agric. Food Chem. 54, 1772-1778.

Garayev, E., Herbette, G., Di Giorgio, C., Chiffolleau, P., Roux, D., Sallanon, H., Ollivier, E., Elias, R., Baghdikian, B., 2017. New sesquiterpene acid and inositol derivatives from Inula montana L. Fitoterapia 120, 79-84.

Girerd, B., Roux, J.-P., 2011. Flore du Vaucluse: troisième inventaire, descriptif, écologique et chorologique, Parthénope. Biotope, Mèze, France.

Gonzalez Romero, M.A., Villaescusa Castillo, L., Diaz Lanza, A.M., Bartolome Esteban, C., Fernandez Matellano, L., 2001. Phytochemistry and pharmacological studies of Inula montana L. Recent Res. Dev. Phytochem. 5, 255-268.

Graves, J.D., Taylor, K., 1988. A comparative study of Geum rivale L. and G. urbanum L. to determine those factors controlling their altitudinal distribution II. Photosynthesis and respiration. New Phytol. 108, 297-304.

Gressot, D., 2010. Le parc naturel régional du Luberon. Petit Futé, Paris.

Guidi, L., Calatayud, A., 2014. Non-invasive tools to estimate stress-induced changes in photosynthetic performance in plants inhabiting Mediterranean areas. Environ. Exp. Bot. 103, 42-52.

Jurkiewicz, A., Ryszka, P., Anielska, T., Waligórski, P., Białońska, D., Góralska, K., Tsimilli-Michael, M., Turnau, K., 2010. Optimization of culture conditions of Arnica montana L.: effects of mycorrhizal fungi and competing plants. Mycorrhiza 20, 293306.

Körner, C., 1999. Alpine Plant Life. Springer Berlin Heidelberg, Berlin, Heidelberg.

Kofidis, G., Bosabalidis, A.M., Moustakas, M., 2007. Combined effects of altitude and season on leaf characteristics of Clinopodium vulgare L. (Labiatae). Environ. Exp. Bot. 60, 69-76.

Liu, W., Yin, D., Li, N., Hou, X., Wang, D., Li, D., Liu, J., 2016. Influence of environmental factors on the active substance production and antioxidant activity in Potentilla fruticosa L. and its quality assessment. Sci. Rep. 6, 28591.

Loreto, F., Schnitzler, J.-P., 2010. Abiotic stresses and induced BVOCs. Trends Plant Sci. 15, 154-166 (Special Issue: Induced biogenic volatile organic compounds from plants).

Maxwell, K., Johnson, G.N., 2000. Chlorophyll fluorescence - a practical guide. J. Exp. Bot. 51, 659-668.

Mooney, H.A. (Ed.), 1991. Response of Plants to Multiple Stresses, Physiological Ecology. Academic Press, San Diego.

Murchie, E.H., Lawson, T., 2013. Chlorophyll fluorescence analysis: a guide to good practice and understanding some new applications. J. Exp. Bot. 64, 3983-3998.

Oh, M.-M., Carey, E.E., Rajashekar, C.B., 2009. Environmental stresses induce healthpromoting phytochemicals in lettuce. Plant Physiol. Biochem. PPB Société Fr. Physiol. Végétale 47, 578-583.

Pérez-Estrada, L.B., Cano-Santana, Z., Oyama, K., 2000. Variation in leaf trichomes of Wigandia urens: environmental factors and physiological consequences. Tree Physiol. 20, 629-632.

Pavarini, D.P., Pavarini, S.P., Niehues, M., Lopes, N.P., 2012. Exogenous influences on plant secondary metabolite levels. Anim. Feed Sci. Technol. 176, 5-16 (Special Issue: Plant Bioactive Compounds in Ruminant Agriculture - Impacts and Opportunities).

Perera-Castro, A.V., Brito, P., González-Rodríguez, Á.M., 2017. Light response in alpine species: different patterns of physiological plasticity. Flora 234, 165-172.

Perry, N.B., Burgess, E.J., Rodríguez Guitián, M.A., Romero Franco, R., López Mosquera, E., Smallfield, B.M., Joyce, N.I., Littlejohn, R.P., 2009. Sesquiterpene lactones in Arnica montana: helenalin and dihydrohelenalin chemotypes in Spain. Planta Med. $75,660-666$.

Ph. Eur, 2017. European Pharmacopoeia Online Version 9.2. http://online6.edqm.eu/ ep902/. (Accessed 13 June 2017).

Picotte, J.J., Rosenthal, D.M., Rhode, J.M., Cruzan, M.B., 2007. Plastic responses to 
temporal variation in moisture availability: consequences for water use efficiency and plant performance. Oecologia 153, 821-832.

Poiroux-Gonord, F., Santini, J., Fanciullino, A.-L., Lopez-Lauri, F., Giannettini, J., Sallanon, H., Berti, L., Urban, L., 2013. Metabolism in orange fruits is driven by photooxidative stress in the leaves. Physiol. Plant. 149, 175-187.

Radušienė, J., Karpavičienė, B., Stanius, Ž., 2013. Effect of external and internal factors on secondary metabolites accumulation in St. John's Worth. Bot. Lith. 18, 101-108.

Ramakrishna, A., Ravishankar, G.A., 2011. Influence of abiotic stress signals on secondary metabolites in plants. Plant Signal. Behav. 6, 1720-1731.

Reynaud, J., Lussignol, M., 1999. Free flavonoid aglycones from Inula montana. Pharm. Biol. 37, 163-164.

Rodriguez-Saona, C.R., Mescher, M.C., Moraes, C.M.D., 2013. The role of volatiles in plant-plant interactions. In: Baluška, F. (Ed.), Long-Distance Systemic Signaling and Communication in Plants, Signaling and Communication in Plants. Springer, Berlin Heidelberg, pp. 393-412.

Rohaçek, K., 2002. Chlorophyll fluorescence parameters: the definitions, photosynthetic meaning, and mutual relationships. Photosynthetica 40, 3-29.

Rouached, H., Pal, S., Rachmilevitch, S., Libault, M., Tran, L.-S.P., 2015. Plants coping abiotic and biotic stresses: a tale of diligent management. BioMed Res. Int. 2015, e754754.

Sampaio, B.L., Edrada-Ebel, R., Da Costa, F.B., 2016. Effect of the environment on the secondary metabolic profile of Tithonia diversifolia: a model for environmental metabolomics of plants. Sci. Rep. 6, 29265.

Scognamiglio, M., D’Abrosca, B., Esposito, A., Fiorentino, A., 2015. Chemical composition and seasonality of aromatic Mediterranean plant species by NMR-Based Metabolomics. J. Anal. Methods Chem. 2015, 258570.

Seca, A.M.L., Grigore, A., Pinto, D.C.G.A., Silva, A.M.S., 2014. The genus Inula and their metabolites: from ethnopharmacological to medicinal uses. J. Ethnopharmacol. 154, 286-310.

Seigler, D.S., 1998. Plant Secondary Metabolism. Springer, US.

Slama, I., M’Rabet, R., Ksouri, R., Talbi, O., Debez, A., Abdelly, C., 2015. Water deficit stress applied only or combined with salinity affects physiological parameters and antioxidant capacity in Sesuvium portulacastrum. Flora - Morphol. Distrib. Funct. Ecol. Plants 213, 69-76.

Sperlich, D., Chang, C.T., Peñuelas, J., Gracia, C., Sabaté, S., 2015. Seasonal variability of foliar photosynthetic and morphological traits and drought impacts in a Mediterranean mixed forest. Tree Physiol. 35, 501-520.

Spitaler, R., Schlorhaufer, P.D., Ellmerer, E.P., Merfort, I., Bortenschlager, S., Stuppner, H., Zidorn, C., 2006. Altitudinal variation of secondary metabolite profiles in flowering heads of Arnica montana cv. ARBO. Phytochemistry 67, 409-417.

Strasser, R., Srivastava, A., Tsimilli, M., 2000. The fluorescence transient as a tool to characterize and screen photosynthetic samples. In: Yunus, M., Pathre, U., Mohanty, P. (Eds.), Probing Photosynthesis: Mechanisms, Regulation and Adaptation. Taylor and Francis, London, UK, pp. 445-483.

Sugier, D., Sugier, P., Gawlik-Dziki, U., 2013. Propagation and introduction of Arnica montana L. into cultivation: a step to reduce the pressure on endangered and highvalued medicinal plant species. Sci. World J. 2013, 414363.

Suzuki, N., Rivero, R.M., Shulaev, V., Blumwald, E., Mittler, R., 2014. Abiotic and biotic stress combinations. New Phytol. 203, 32-43.

Tela Botanica, 2016. Tela Botanica. http://www.tela-botanica.org/. (Accessed 6 September 2016).

Tian, D., Tooker, J., Peiffer, M., Chung, S.H., Felton, G.W., 2012. Role of trichomes in defense against herbivores: comparison of herbivore response to woolly and hairless trichome mutants in tomato (Solanum lycopersicum). Planta 236, 1053-1066.

Todorova, M., Trendafilova, A., Vitkova, A., Petrova, M., Zayova, E., Antonova, D., 2016 Developmental and environmental effects on sesquiterpene lactones in cultivated Arnica montana L. Chem. Biodivers. 13, 976-981.

Wolfe, M.D., Tonsor, S.J., 2014. Adaptation to spring heat and drought in northeastern Spanish Arabidopsis thaliana. New Phytol. 201, 323-334.

Yuliani, Soemarno, Yanuwiadi, B., Leksono, A.S., 2015. The relationship between habitat altitude, enviromental factors and morphological characteristics of Pluchea indica, Ageratum conyzoides and Elephantopus scaber. OnLine J. Biol. Sci. 15, 143-151. 